Cornell Law Library Scholarship@Cornell Law: A Digital Repository

Cornell Law Faculty Publications

Faculty Scholarship

4-1974

\title{
An Empirical Survey of Price Fixing Conspiracies
}

George A. Hay

Cornell Law School, george.hay@cornell.edu

Daniel Kelley

U.S. Department of Justice

Follow this and additional works at: http://scholarship.law.cornell.edu/facpub

Part of the Antitrust and Trade Regulation Commons, and the Commercial Law Commons

\section{Recommended Citation}

Hay, George A. and Kelley, Daniel, "An Empirical Survey of Price Fixing Conspiracies" (1974). Cornell Law Faculty Publications. Paper 1121.

http://scholarship.law.cornell.edu/facpub/1121

This Article is brought to you for free and open access by the Faculty Scholarship at Scholarship@Cornell Law: A Digital Repository. It has been accepted for inclusion in Cornell Law Faculty Publications by an authorized administrator of Scholarship@Cornell Law: A Digital Repository. For more information, please contact jmp8@cornell.edu. 


\title{
AN EMPIRICAL SURVEY OF PRICE FIXING CONSPIRACIES*
}

\author{
GEORGE A. HAY and DANIEL KELLEY \\ U.S. Department of Justice
}

$\mathrm{T}$ HIS paper reports on a study of recent Antitrust Division horizontal price fixing cases. The objective of the study was to determine if there has been a specific set of characteristics associated with the product or product markets that have been the subjects of price fixing. If such a pattern exists, it might provide empirical insight into some aspects of oligopoly behavior. From a policy point of view, any pattern that is found could be used in a positive enforcement program designed to investigate the "most likely" areas of price fixing. Section I reviews the academic literature which has dealt with the problem of horizontal conspiracy; ${ }^{1}$ Section II describes the sample and the methodology used in the study; and Section III summarizes the results.

For present purposes collusion will be defined as formal or explicit agreement among competitors. Collusion is normally viewed as a means for firms without significant individual market power to earn greater than competitive profits. The structural characteristics which are hypothesized to affect the

* This paper reflects our own view and does not necessarily represent the position of the Antitrust Division. We are grateful for helpful comments from several colleagues. Joseph Mashi provided invaluable assistance in gathering the data sources.

1 Recent contributions in this area include: George J. Stigler, A Theory of Oligopoly, in The Organization of Industry 39 (1968); Peter Asch, Collusive Oligopoly: An Antitrust Quandary, John M. Kuhlman, Nature and Significance of Price Fixing Rings, \& Walter B. Erickson, Economics of Price Fixing, all in 2 Antitrust Law \& Econ. Rev. 53-122 (1969). Joseph C. Gallo, Oligopoly and Price-Fixing: Some Analytical Models, 4 Antitrust Law \& Econ. Rev. 101 (1970); Roger D. Blair, The Sherman Act and the Incentive to Collude, 17 Antitrust Bull. 433 (1972); Richard A. Posner, Oligopoly and the Antitrust Laws: A Suggested Approach, 21 Stan. L. Rev. 1562 (1969); James M. Clabault \& John F. Burton, Jr., Sherman Act Indictments 1955-65, (1966); Roger Sherman, Oligopoly, An Empirical Approach (1972). For a textbook treatment see Frederick M. Scherer, Industrial Market Structure and Economic Performance chs. 6, 7, \& 19 (1970). Richard A. Posner, A Statistical Study of Antitrust Enforcement, 13 J. Law \& Econ. 365 (1970), provided both a point of departure and a sense of direction to this paper. 
incentive to engage in collusive behavior can be enumerated under two categories: (1) those conditions which lower the difficulty of achieving effective collusion by making coordination easier; and (2) those conditions which raise the cost of non-collusive conduct by increasing the potential instability of non-collusive behavior. The factors most often cited in the first category are fewness of numbers, concentration, product homogeneity, industry social structure, inelasticity of demand, and sealed bidding. Lumpiness and infrequency of orders and a high ratio of fixed to marginal costs are factors which fall into the second category.

Effective coordination through collusion requires the ability for the firms involved not only to reach but also to enforce an agreement. Enforcement involves the detection and possibly the disciplining of cheaters. The policing of cheating is important because successful collusion, by raising price above the competitive level, creates incentives for individual conspirators to slightly lower their prices and thus greatly increase their sales. Each of the characteristics above must be evaluated in the light of its effect upon coordination and enforcement.

\section{Factors Which Facilitate Coordination}

a. Fewness of Numbers

Fewness of numbers should be an important factor in the ability of firms to collude successfully. In the process of agreeing upon a price to be set, divergent ideas are a handicap. The conspirators can have divergent views about the optimal price because their cost structures vary or because their views about demand conditions may differ; the smaller the number of competitors the less likely it is that these differences will appear.

In his theory of collusion, Stigler ${ }^{2}$ emphasizes the importance of the cheating factor. By analyzing the conditions under which secret price reductions will be detected he reaches the conclusion that, holding variables such as the number and size distribution of the buyers constant, the likelihood of competitors detecting each other's price reductions decreases with the number of firms involved. If these reductions can be easily detected either they will cease or the conspiracy will collapse. The implication is that the smaller the number of firms selling in the market in question, the higher the probability that a conspiracy will be successful, and thus the greater the incentive to enter into such a conspiracy.

\section{b. Concentration}

It is frequently argued that firms in highly concentrated industries often do not need to collude explicitly, but can rely on tacit collusion or "conscious

2 George J. Stigler, supra note 1. 
parallelism" to achieve a near-monopoly price. Alternatively it is possible that the high degree of interdependence which characterizes oligopolistic markets naturally leads to collusive activity. If the latter is true, high degrees of concentration lead to a greater likelihood that this interdependence will be recognized and that actual collusion will follow.

\section{c. Product Homogeneity}

Product homogeneity is among the characteristics frequently cited as facilitating collusive behavior; however the term can be used in at least three senses. One way to define homogeneity is linked to the elasticity of substitution between competitors' products. If the products (or product lines) of two competitors are perfect substitutes for each other, then the "product" is homogeneous. Sometimes, however, homogeneity is used to describe a situation in which the product itself is not complicated. An example will illustrate the difference. Purchasers of steel castings can probably acquire a casting of given specifications from any casting manufacturer. In the sense of the first definition above castings are a homogeneous product. However casting manufacturers produce a wide variety of types and grades of castings, using a wide variety of alloys and "extras," with no single type of casting accounting for a large percentage of total output. From this point of view the product is heterogeneous. To say that in the latter case the product has not been defined narrowly enough overlooks the nature of the problem at hand, which is the ability of competitors to reach a mutually satisfactory agreement.

If a product is homogeneous under both definitions a single price can be negotiated by the conspirators. However, if a product is heterogeneous under either definition an array of prices must be negotiated. This is an inherently more difficult task unless some sort of formula or customer allocation scheme can be arranged.

Still another type is homogeneity over time. If product characteristics remain stable through time then agreement is inherently easier to reach and maintain. Therefore, industries with high rates of technological change should not be expected to be found engaging in collusion with the same frequency as industries without rapid change.

In sum, inter-firm, intra-firm and over-time product differences, by increasing the number of issues to be negotiated, make collusion more difficult.

\section{d. Demand Inelasticity}

The more inelastic is industry demand, the greater are the potential rewards to the price fixers. Concomitantly the smaller will be the sacrifice in terms of capacity utilization. 


\section{e. Sealed Bidding}

The Federal Government's procurement practices are said to facilitate coordination among firms who bid on Government contracts. The results of sealed bid competitions are announced publicly, thus providing conspirators with an excellent means of monitoring the incidence of cheating. If it is a certainty that a firm that cheats will be detected by co-conspirators the incentive to do so will obviously be reduced.

\section{f. Industry Social Structure}

This characteristic, although it falls within the realm of sociology rather than economics, cannot be ignored. In the formative stages of a conspiracy, unless it is organized under the aegis of an organization such as the NRA, someone must take the lead in making the contacts and organizing the meetings. Given the illegality of such arrangements some competitors must be coaxed into joining, and a dominant individual will often overcome the inertia and take the lead. Such a person can often exert enough pressure to overcome characteristics-which might otherwise prevent a conspiracy from forming. Such an individual may also be necessary to the maintenance of a scheme by acting as a chairman and policeman of meetings. Conversely, a maverick in the industry, by virtue of his desire for independence may prevent conspiracy in an industry otherwise very ripe for it.

\section{Factors Which Increase the Risk of Non-Collusive Coordination}

Intended for discussion in the section are those attributes of a market which are often said to lead to excessive or "cut-throat" competition. When such behavior occurs it is argued that collusion will be used in an attempt to maintain discipline in the industy. A paradox exists in that the factors which lead to "excessive" competition in the first place, frequently are those that increase the likelihood of cheating on any collusive agreement that evolves. The preliminary conclusion is that where these factors are present collusion is likely to be attempted but is not likely to be of lasting duration. The only reason that collusion is attempted in these circumstances is that the payoff, if even for limited duration, can be high.

\section{a. Lumpiness and Infrequency of Orders}

Stigler points out that secret price cuts will not be made to ". . . buyers whose purchases fall below a certain size relative to his aggregate sales." It follows that if a few buyers purchase large quantities in relation to a firm's aggregate sales there will be great temptation for the firm to grant

3 Id. at 43. 
price reductions to such buyers either to keep them as customers or win their business from another competitor. In the absence of collusion prices will be driven down towards the competitive level. Of course, even if collusion is attempted it will not be successful unless cheating is policed. Nevertheless collusion may be the only potential mechanism for raising industry profits. A corollary, applicable to the conditions listed in Section I above, is that "... collusion will often be effective against small buyers even where it is ineffective against large buyers."

\section{b. High Fixed Costs}

Price wars are a phenomenon often associated with high fixed costs industries. When demand falls (during a recession for example) unutilized capacity develops. It is tempting in these circumstances for a firm to reduce its price, expand output and sales and thus generate revenue to offset the burden of its high fixed costs. If all firms do this a downward price spiral may be the result. It is not surprising therefore for the firms to attempt to prevent or stop such a spiral by an agreement. Even if an agreement is reached, it may be a fragile one, subject to disintegration during the next downturn.

\section{Methods of Collusion}

Collusion is not a uniform concept. Different industry structures can, $a$ priori, be expected to lead to different types of collusive conduct. Where, for example, numbers of competitors are large or where the product differs among transactions (for example, construction) regularly scheduled formal meetings with or without the aid of a trade association can be expected. Conversely, with small numbers and/or a simple product, communication can be effective under less formal, but nevertheless quite illegal, circumstances. Where purchases are repetitive a single list price (or a price list) may be agreed upon -with or without the added attribute of customer allocation; but for nonrepetitive purchases, job or territorial allocation, where feasible, may be used in conjunction with a complementary bidding system.

II

This section deals with the sample and the methodology used in the present study. Public information about Antitrust Division price fixing cases comes from two sources: (1) the court record when cases proceed to trial, and (2) the indictments, complaints and press releases which accompany a case filing. Information from the first source is limited due to the fact that most cases are settled by nolo contendere pleas and therefore no substantive

4Id. at 44 . 
court record is generated. ${ }^{5}$ Indictments, complaints and press releases contain some useful information; however most of these documents are written in a standard form detailing little more than the technical nature of the violation, the names of the defendants and the nature of the product. Press releases sometimes give an indication of the volume of commerce involved in the alleged violation but provide little information beyond that found in the indictments or complaints.

For the present study the fact memoranda and other supportive documents prepared by Antitrust Division staff which investigated the violation were also examined. ${ }^{6}$ These memoranda have some limitations but in general provide a rich source of detail. ${ }^{7}$ Because they are written by the legal staff in preparation for trial, fact memoranda describe in full the conduct of individual conspirators. Less attention is paid to structural matters but some relevant information is available as a by-product. Very little attention is paid to performance since, of course, it is largely irrelevant to proving illegality in the type of case investigated.

All Section 1 criminal cases which were filed and won in trial or settled by nolo contendere pleas from January 1963, to December 1972, were examined. 8 Cases involving vertical agreements (between producers and distributors for example) were excluded, as were agreements which were not covert. Thus the recent cases involving alleged price fixing for the services of various professional groups were excluded.

6 A plea of nolo contendere or "no contest" entered in a criminal case is equivalent to a plea of guilty for purposes of sentencing but is not an admission of guilt by the defendant. A trial is not necessary when a nolo contendere plea is accepted by the court. The courts occasionally accept nolo contendere pleas over the objection of the Department of Justice.

${ }^{6} \mathrm{~A}$ fact memorandum is a summary of the evidence which has been gathered up to the point at which a decision to file a case must be made. In a criminal case the fact memorandum is ordinarily written after all Grand Jury testimony has been heard but before an indictment is presented to the jurors. The fact memoranda were found in Department of Justice files. These files are exempt from the Freedom of Information Act and therefore are not available to the public. We have attempted to provide as much information as possible consistent with the legal constraints.

7 To cite one example, many indictments will allege that co-conspirators were involved; however they are usually not named and their relation to the conspiracy is unknown. The fact memorandum will indicate their names and their exact relationship to the indicted firms.

8 The Minnesota bank cases, Trade Reg. Rep. Case Nos. 1734-1736 (Transfer Binder for U.S. Antitrust Case Summaries 1961-1970), and the Los Angeles pipe cases, Trade Reg. Rep. Case Nos. 1785-1789 (Transfer Binder for U.S. Antitrust Case Summaries 19611970) were excluded because no data were available. United States v. Bethlehem Steel Co., Trade Reg. Rep. Case No. 1871 (Transfer Binder for U.S. Antitrust Case Summaries 1961-1970) was not included because of the ambiguous result; of a total of 18 counts charged against 11 defendants, 5 nolo contendere pleas were accepted; the remaining counts were dismissed. 
Each case in the sample was abstracted for product market, geographical market, names of the conspirators and, to the extent possible, their size distribution. Then any useful information about the particular product and market characteristics was noted. Finally, the conspiracy was described and the method of detection, if that information was available, was listed. The information about the conspiracy recorded included the origins of the conspiracy (if known), the method of operation, and any available knowledge of its success.

\section{III}

Some of the results of the study are summarized in the appendix. ${ }^{9}$ The cases there are listed by $\mathrm{CCH}$ Trade Regulation Reports ("Blue Book") number, the name of the product and (in parentheses following the product name) the Standard Industrial Classification number (SIC).$^{10}$ The next column indicates whether the geographical scope of the conspiracy was local, regional or national.

The information in the next three columns is designed to describe the number and size distribution of the firms in the industry. The traditional four-firm concentration ratio is computed from sales data found in the fact memoranda. ${ }^{11}$ In most cases the data are taken from the last year in which the conspiracy was fully operative. Information which could be used to gauge temporal changes in the market shares was not available. Exact concentration ratios could not be computed in every case. In some instances market share data were presented for all of the firms which were factors in the market being investigated; in other instances data were presented only for the conspirators. In the latter situation, if there was reason to believe that the conspirators supplied a substantial portion of the market, the relative share of the top four is listed in the table with a "less than" sign. Such numbers represent the upper limit of the actual concentration ratio but provide an approximation. When the latter technique could not be used because data for too many firms were lacking or when no market share data appeared in the fact memorandum, market concentration is not reported.

9 Infra at 29. Regulations pertaining to Grand Jury evidence precludes disclosure of some of the information which was gathered.

10 Summaries of cases listed in order by "Blue Book" number can be found in Trade Reg. Rep. (Transfer Binder for U.S. Antitrust Case Summaries, 1961-1970) and Trade Reg. Rep. If $45,070-45,072$ at 53,201-53,514. Note that the four-digit Census industry number is also reported. The products in the sample would in most cases be assigned five, six, or seven digit numbers by the Census Bureau. The Standard Industrial Classification (SIC) numbers were assigned by the authors.

11 The resultant concentration ratios are unique in one sense-they are based on a product concept narrower than the common four-digit "industry" level. The possible importance of this level of detail will be discussed infra. 
The figure reported next is the number of conspirators (followed in parentheses by the combined market share of all of the conspirators). The number of conspirators is not the same as the number of indicted firms; if there were co-conspirator firms they are included, or if two or more - indicted firms were actually controlled by one set of interests, only one of the entities is counted. A firm may be listed as a co-conspirator but not indicted if the evidence against it was of lower quality than the evidence against the indicted firms or if the firm did not actually participate in all of the meetings but had knowledge of the collusive activity. The number of competitors in the market column gives the number of firms who were known to be factors in the market.

The "Trade Association" column simply indicates whether a trade association existed, and if so, if it was in some way involved in the conspiracy.

The column entitled "Nature of the Buyers" is intended as a rough indicator of the type of market in which the conspirators sold their products or services. If the buyers were a very heterogeneous group, or if their identity simply was not known, the entry is blank. An important feature of this column is that if the fact memorandum indicated that significant amounts of sales were made to Government agencies this is reported.

"Nature of the Offense" is a description of the conduct in which the conspiring firms engaged. Such conduct could range from simple price fixing to agreements on various terms of sale to bid-rigging on a job by job basis.

The determinants of collusive behavior listed in Section I can be evaluated in the light of both the information presented in the appendix and other information available from the case abstracts which. were prepared. The sample of cases consists of conspiracies which were both discovered and successfully prosecuted; as such they are not necessarily a random sample of all existing conspiracies. This fact may tend to bias the results; however the cases in the sample were discovered in a variety of ways such as customer complaints, observation of performance by Government agencies, and industry informants (see Table 1). The variety of methods of detection tends to argue for the proposition that most conspiracies are subject to possible detection although it is probably reasonable to assume that concentrated industries are more likely than unconcentrated ones to escape detection.

\section{a. Fewness of Numbers}

If the four cases in which the number of conspirators is fifty or more are excluded, the average number of firms involved in the conspiracy is 7.25. Table 2 below provides a more useful summary of the number of conspiring firms per conspiracy. In 79 per cent of the conspiracies ten or fewer firms were involved. The number of firms is a variable which was very much on 
TABLE 1

Method of Detection in 49 Cases $a$

\begin{tabular}{lc}
\hline \multicolumn{1}{c}{ Method } & Number of Cases \\
\hline Grand Jury investigation in another case & 12 \\
Complaint by a competitor & 10 \\
Complaint by a customer & 7 \\
Complaint by Local, State or Federal Agency & 6 \\
Complaint by current or former employees & 3 \\
Complaint by Trade Association Official & 2 \\
Investigation of conduct or performance initiated by Antitrust & 2 \\
Division & 2 \\
Newspaper account & 2 \\
Referred to Antitrust Division by the Federal Trade Commission & 1 \\
Complaint by anonymous informant & 1 \\
Merger investigation & 1 \\
Private suit & $\frac{1}{49}$ \\
Total &
\end{tabular}

a This information was not available for the remainder of the cases in the sample.

the minds of the potential conspirators; in one of the cases studied the product which was to be subject to agreement was deliberately defined narrowly in order to keep the number of participants small.

The results also show that in many cases larger groups do conspire. It has often been assumed that a formal trade association is the basic mechanism which allows (or is used for) large group collusion. Table 2 also shows the distribution of trade association involvement by number of conspirators. In seven out of eight cases with more than fifteen firms in the conspiracy, a formal industry trade association was involved. The table also shows that trade associations were often used with small numbers, but were not necessarily used even with groups of between ten and fifteen where an association was involved in only four out of twelve cases. What the table fails to reveal is that many conspiracies were in fact highly organized with chairmen, rules of order, agendas and regularly scheduled meetings, but without the cover of a formally organized industry trade association.

A comparison of the number of conspirators column with the number of firms in the market column shows that it is not necessary for a conspiracy to include all of the firms in the market to exist, or indeed, to be successful. It is interesting to speculate on the role of the non-conspirators. In some cases they may occupy product or territorial submarkets not recognized by the staff which wrote the fact memorandum. In general, they seem to be the smallest competitors. It is difficult to believe that these non-conspirators were unaware of the conspiracy. It might be assumed that they were willing silent accomplices living under the price umbrella provided by the conspirators. 


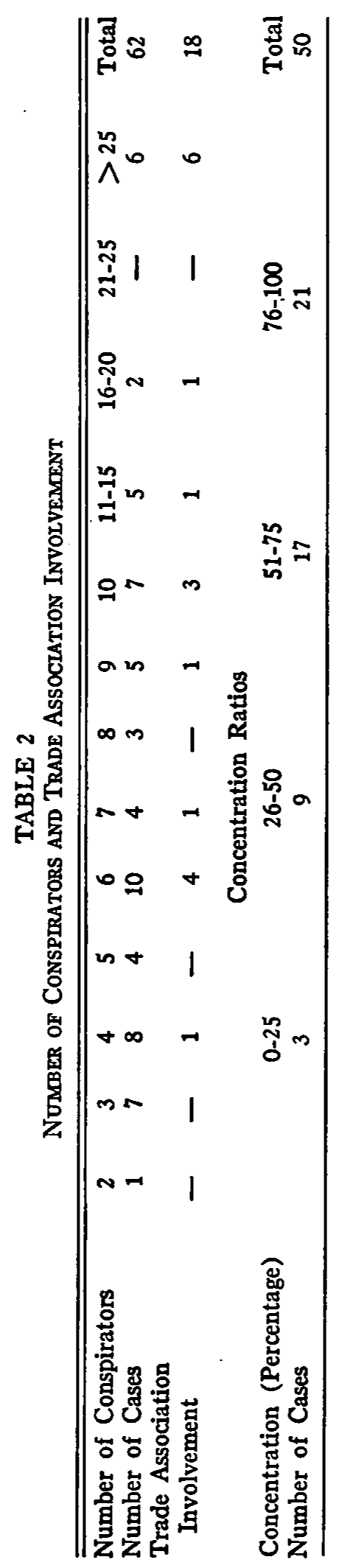




\section{b. Concentration}

Information which could be used to compute concentration ratios was more likely to be available for relatively concentrated industries. Therefore a table listing only the concentration ratios shown in the appendix would be biased towards high values. In those situations in which data were not available, if the total number of firms in the market was known, a "minimum concentration ratio" was estimated by dividing the number of firms into 100 and multiplying by 4. "Minimum concentration ratios" could also be calculated from the market share information reported in the number of conspirators column. In thirty-eight of fifty cases for which estimates could be made the concentration ratio was greater than 50 per cent (see Table 2). This suggests that concentration is an important determinant of the ability of firms to collude. An examination of those cases in which minimum concentration ratios could not be calculated (because it was not felt that they would be appropriate or because the total number of firms in the market was not known) indicates that the conclusions would not be changed even if they could be included. ${ }^{12}$

Clabault and Burton ${ }^{13}$ analyzed structure-conduct relationships in industries indicted under the Sherman Act between 1955 and 1965. Their conclusion was that conspiracies were most likely to develop in relatively unconcentrated markets. Clabault and Burton used Census concentration data at the four-digit level, while the concentration ratios reported herein, are oriented to the specific products that were the subject of conspiracy.

When the 1967 Census four-firm concentration ratios for the four-digit SIC industries in which the products in our survey are classified were examined, and compared to the product concentration ratios as reported in the appendix, the Census ratios for the products of the thirteen national conspiracies were lower than the product concentration ratios by an average of 39 percentage points (see Table 3 ). Thus, although the Clabault and Burton sample differs from that used here, it is reasonable to infer that their use of four-digit Census concentration figures resulted in a serious underestimate of the "true" level of concentration in the product markets in which price fixing conspiracies were found. ${ }^{14}$

The implications of this result are significant. Despite the writings of

12 Calculations for the share of the largest firm divided by the share of the largest four were made. These show that there were many situations in which asymmetric oligopoly was present. However, this tendency was not dominant and no special significance can be attached to it.

13 Supra note 1.

14 It may, of course, be true that all product markets as defined here are generally much more concentrated than the Census categories and the sample simply reflects this. We know of no reason why this should be true a priori however. 
TABLE 3

Concentration Ratios in National Cases

\begin{tabular}{cccc}
\hline \hline Blue Book Number & SIC Number & Census Ratios & Fact \\
\hline 1743 & 3312 & $48 \%$ & $85 \%$ \\
1744 & 3494 & $14 \%$ & $67 \%^{\mathfrak{a}}$ \\
1748 & 2515 & $26 \%$ & $61 \%$ \\
1749 & 2542 & $24 \%$ & $60 \%$ \\
1751 & 3323 & $20 \%$ & $32 \%$ \\
1754 & 3452 & $18 \%$ & $97 \%$ \\
1778 & 2339 & $16 \%$ & $69 \%$ \\
1796 & 3312 & $48 \%$ & $59 \%$ \\
1802 & 3623 & $38 \%$ & $77 \%$ \\
1883 & 3999 & $10 \%$ & $77 \%$ \\
1890 & 3545 & $20 \%$ & $56 \%$ \\
1921 & 3261 & $62 \%$ & $76 \%$ \\
1965 & 3432 & $28 \%$ & $64 \%$ \\
Average & & $28.6 \%$ & $67.7 \%$ \\
\hline
\end{tabular}

- Estimated from partial market share data.

Stigler and Posner, it has frequently been assumed that conspiracy would be largely restricted to relatively unconcentrated industries, since high concentration would permit extensive non-collusive coordination through what has been termed "conscious parallelism." This assumption has been based primarily on the gross benefits of collusion which are almost surely higher for unconcentrated industries for whom non-collusive coordination is only a remote possibility.

The results of the present study however, suggest that the low cost of planning and enforcing a conspiracy and the smaller likelihood of being caught in concentrated markets, are equally if not more significant factors in stimulating conspiracy. ${ }^{15}$ This is not to suggest that some non-collusive coordination does not take place: but it now appears possible that some of the non-competitive price levels alleged to exist in concentrated industries may be the result not of "conscious parallelism" but of formal conspiracy.

\section{c. Homogeneity}

A column to show the subjectively estimated degree of inter-firm homogeneity is not presented because virtually all of the entries would read "high" product homogeneity. In terms of the simplicity of the product there appears to be some variety, although most of the products seem to be relatively simple. Some complicated products or services can be allocated on a job-by-job

15 It should be kept in mind that most of the conspiracies were found in concentrated markets even though $a$ priori these are the conspiracies which are most likely to escape detection. Thus if there is a bias, it should result in the underreporting of conspiracies in markets with high concentration. 
basis and therefore do not present a great obstacle to coordination. Moreover, even where differentiated or complicated products are involved competitors appear to have isolated some factors which they can usefully agree upon. An agreement to delay end of season discounts in the swimming suit case (No. 1778 in the appendix) is an example.

\section{d. Inelasticity of Demand}

Little or no evidence from fact memorandum sources is available. ${ }^{16}$

\section{e. Sealed Bidding}

Sealed bidding, where the results are announced, was a factor in some cases. However, it is interesting to note that situations were found in which bids to Government agencies were specifically excluded from the agreements. Motivation for this behavior apparently derived from the belief that collusive activity is more likely to be detected and prosecuted if it is directed against the Federal Government. There were other situations in which market segments were not included in agreements in order to reduce potential friction and this may account for deliberate exclusion of Government bids. In any event, a look at the nature of the offense column shows that bid-rigging was a popular form of conduct.

\section{f. Social Structure}

The social structure variable cannot be quantified or briefly described in a table. Suffice it to say that the fact memoranda demonstrated that a dominant individual can force a group of firms to overcome natural barriers to coordination such as large numbers or low concentration ratios. This may explain much of the large group collusion which occurred.

Where the firms are all located in a single area, collusion seems to develop quite naturally and Adam Smith's oft quoted maxim is confirmed: "People of the same trade seldom meet together, even for merriment and diversion, but the conversation ends in a conspiracy against the public, or in some contrivance to raise prices."

\section{g. Lumpiness and Infrequency of Orders}

Evidence relating to situations in which individual sales occur infrequently and/or account for a large share of total output can be derived from the

\footnotetext{
16 However, the Houthakker and Taylor estimates of short-run demand elasticity for four industries which overlapped our sample were all less than 1 (in absolute value), thus partially confirming the proposition that conspiracy is more likely when demand is inelastic. See H. S. Houthakker \& Lester D. Taylor, Consumer Demand in the United States: Analyses and Projections (1970).
} 
"nature of the offense" and "nature of the buyers" columns. If bid-rigging and/or allocation of jobs were involved then it can be assumed that orders were relatively large compared to total sales; this could also be assumed to be true if the buyers market or segments thereof tended toward oligopsony. Bid-rigging was a factor in fifteen cases. Several of those were related to construction, an activity that is inherently "lumpy."

\section{h. High-Fixed and Low Marginal Costs}

Any information about the ratio of fixed to marginal costs must be inferred from prior knowledge of the industries in the sample. Industries with such characteristics can be identified, but no strong pattern appears to emerge.

\section{i. Duration}

Theoretically, those industries with structural characteristics most conducive toward conspiratorial conduct should display the most success as measured by the duration of the conspiracy. Success was plotted against both the number of firms and concentration in order to provide a rough test of this proposition. Since most of the cases had ten or fewer conspirators the dispersion of observations was not great enough to allow any significant pattern to emerge. The most that can be said is that numbers as large as ten will, in certain circumstances, still allow collusion to continue for long periods of time. The concentration-years observations show a clearer pattern; the preponderance of conspiracies lasting ten or more years were in markets with high degrees of concentration. In those industries where attempts were made to organize large numbers of firms, the conspiracies were generally discovered very quickly. Details of some of the large-group organizational meetings were often printed in local newspapers.

Details concerning the beginning of the conspiracies were often available although there were many situations in which the agreements had been in existence for so long that no one could remember the origins. Several conspiracies had their roots in the NRA. Some meetings which began then continued for decades. One conspiracy began with discussions incident to the meetings of a Webb-Pomerene export association. Many, by far the largest number, were organized in response to price wars or general lack of discipline in the market.

\section{Conclusions}

A brief summary of our empirical results would be that conspiracy among competitors may arise in any number of situations but it is most likely to 
occur and endure when numbers are small, concentration is high and the product is homogeneous. We suspect these results will conflict with at least some previously held opinions on the expected locus of conspiracy, and conversely on the ability of oligopolists to regularly attain monopoly profits through tacit collusion.

This is not to suggest that tacit collusion does not occur or that where it occurs it cannot be attacked under existing antitrust laws, ${ }^{17}$ or that a program of deconcentration such as suggested by Senator Hart's proposed Industrial Reorganization Act is either unnecessary or unjustified. It does suggest however that some of the non-competitive pricing attributed to concentrated industries is reachable even under a fairly conservative interpretation of current laws. To discover this kind of conduct would require investigations in those industries for which product markets display the characteristics that appear to be associated theoretically and empirically with collusion. Prime candidates would obviously be industries with a past history of conspiracy. To go much further would require concentration data at something like the seven-digit SIC level for regional or local markets. If such data cannot or will not be made available, however, the relative advantages of this approach to concentrated industries is sharply diminished.

A second implication of our findings has to do with relief. Very little previous work has been done in the area of structure-conduct relationships of the type investigated here. Perhaps as a result of this, scant attention has been paid to structural remedies in Sherman Act Section 1 cases.

The traditional remedies of fines and criminal convictions are generally considered to be inadequate as currently applied. ${ }^{18}$ Legislative proposals have been made to increase fines in criminal antitrust cases. A supplementary (or alternative) approach would be to apply the court's powers to reorganize offending industries.

Justification for the reorganization approach is provided by two sorts of evidence: (1) The bulk of the violations prosecuted by the Antitrust Division appear to be in concentrated markets. Concentration and fewness of numbers can be said to facilitate (if not, in some instances cause) collusion. The most effective (if not the only effective) means to alter behavior, therefore, may be to alter the structure. ${ }^{19}$ (2) Industries which are found to be colluding in

17 See Richard A. Posner (1969), supra note 1.

18 See Roger D. Blair, supra note 1.

19 Obviously, this is likely to be an attractive remedy only where the firms involved operate two or more plants. Presumably it would not have to be the case that both plants currently serve the narrow geographic or product market in which the conspiracy occurred for dissolution to be effective however. Creating separately-owned entities can be beneficial in two ways even though the "new" firm is not currently in the same geographic or product market. First, because of its experience in serving its own market, the 
one local market are often to be found colluding in other local markets. The number of dairy, bread, concrete and linen supply cases in the sample attest to this fact. If anything, this is stronger evidence of the structure-conduct link. Corollary evidence is that industries colluding at one point in time often can be found to be colluding at later points in time, in spite of Antitrust action in the interim.

In several cases the Antitrust Division has sought the dissolution of industry trade associations. The current study demonstrated that trade associations are often used as a coordinating device, especially when more than a given number of firms are involved. The logic of altering the structure of some industries by requiring the dissolution of their trade sssociations might be extended to breaking up industries with small numbers of competitors when other structural conditions permit.

The demonstration effect of moving for dissolution or divestiture in a price fixing case should not be overlooked. The electrical conspiracy cases seem to have done more for the enforcement of Section 1 than all of the cases prosecuted previous to them. As a start, applying dissolution to habitual offenders may provide the publicity needed to raise further the perceived cost of violating the antitrust laws and thus force compliance by firms in industries prone to conspiracy.

new firm probably faces lower barriers to entry for establishing a new plant in the relevant market. Second, even without actually building a new plant, the new company may influence the behavior of firms in the relevant market by its status as a potential entrant. 
PRICE FIXING CONSPIRACIES

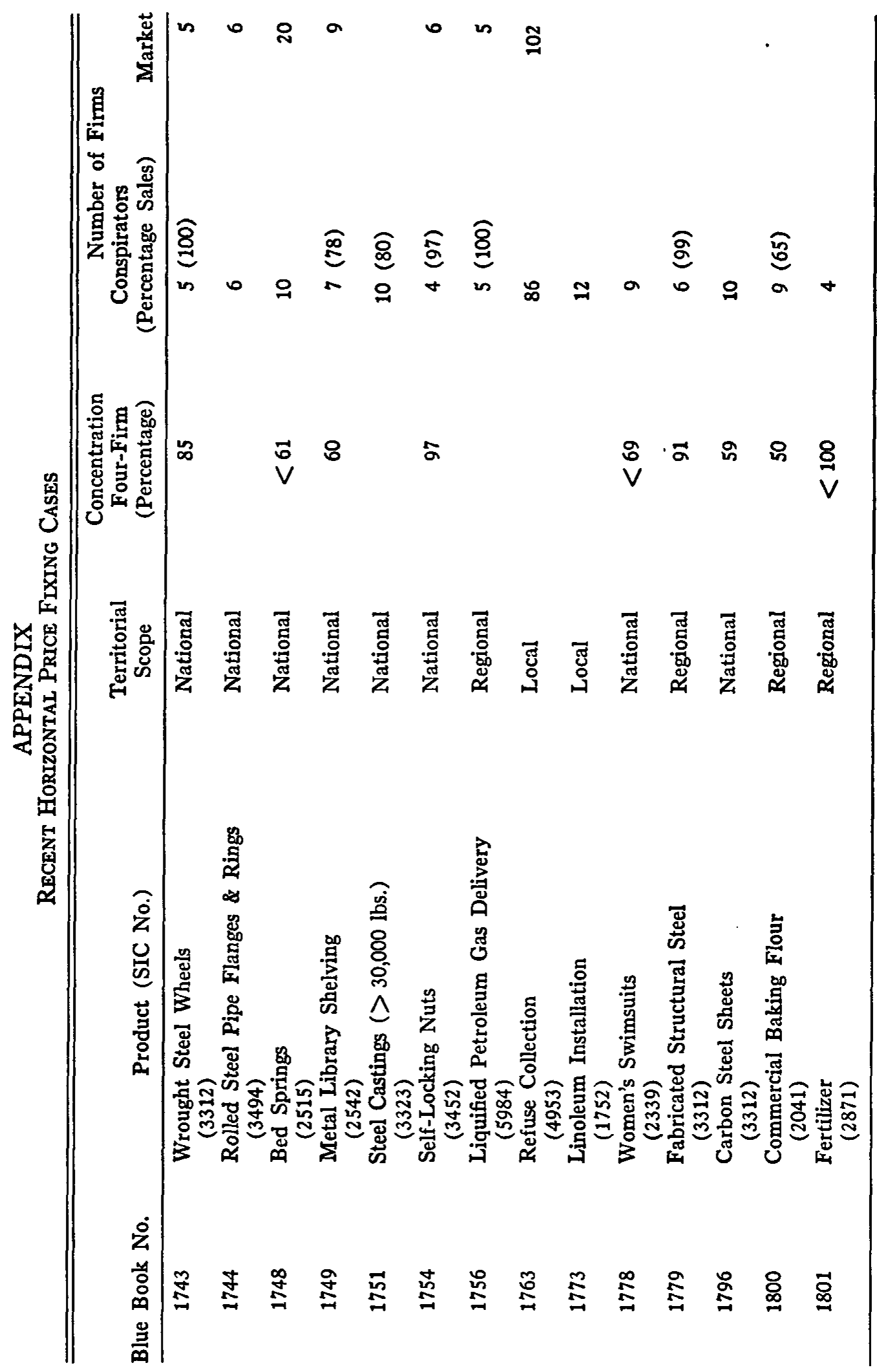




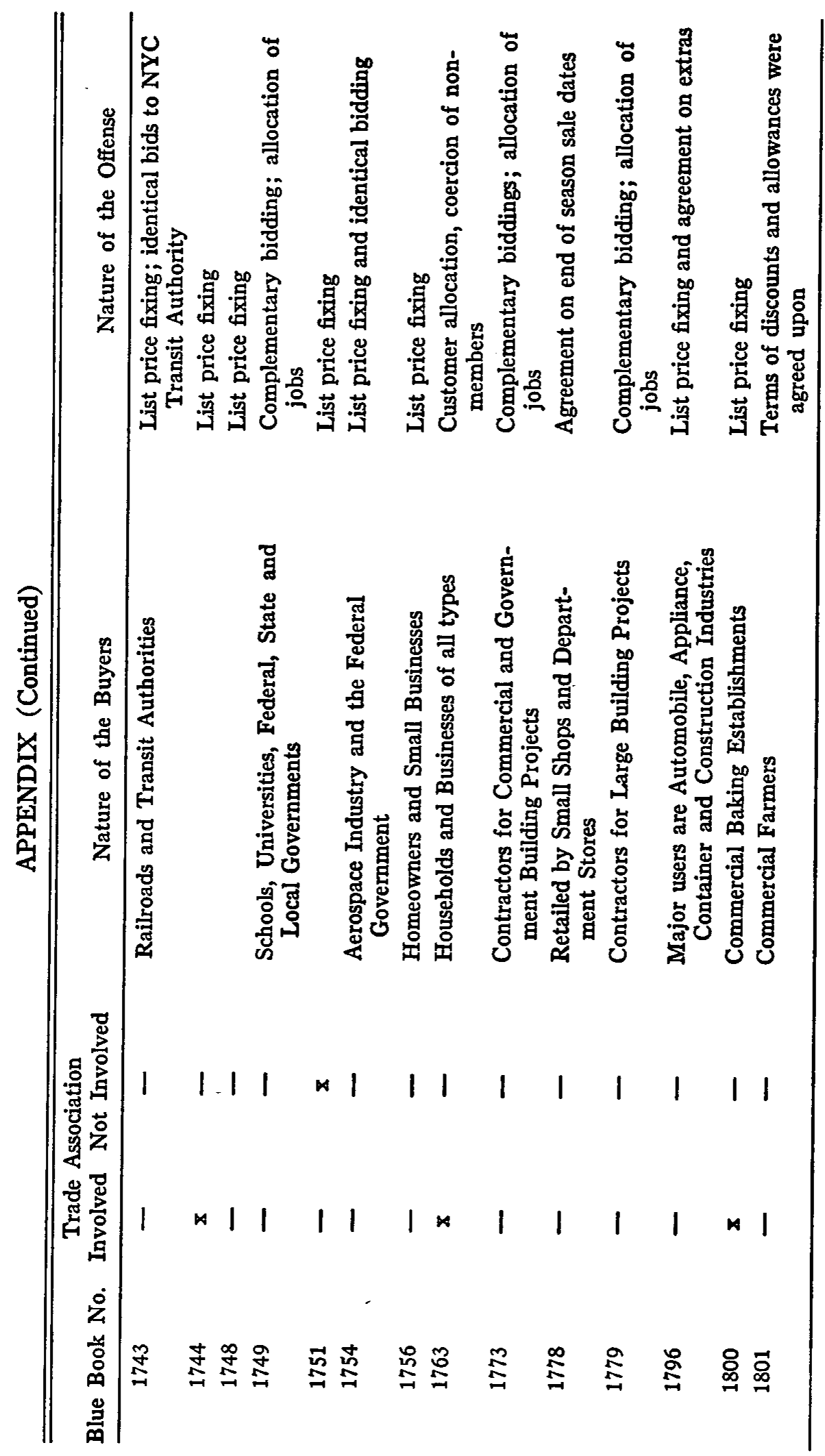




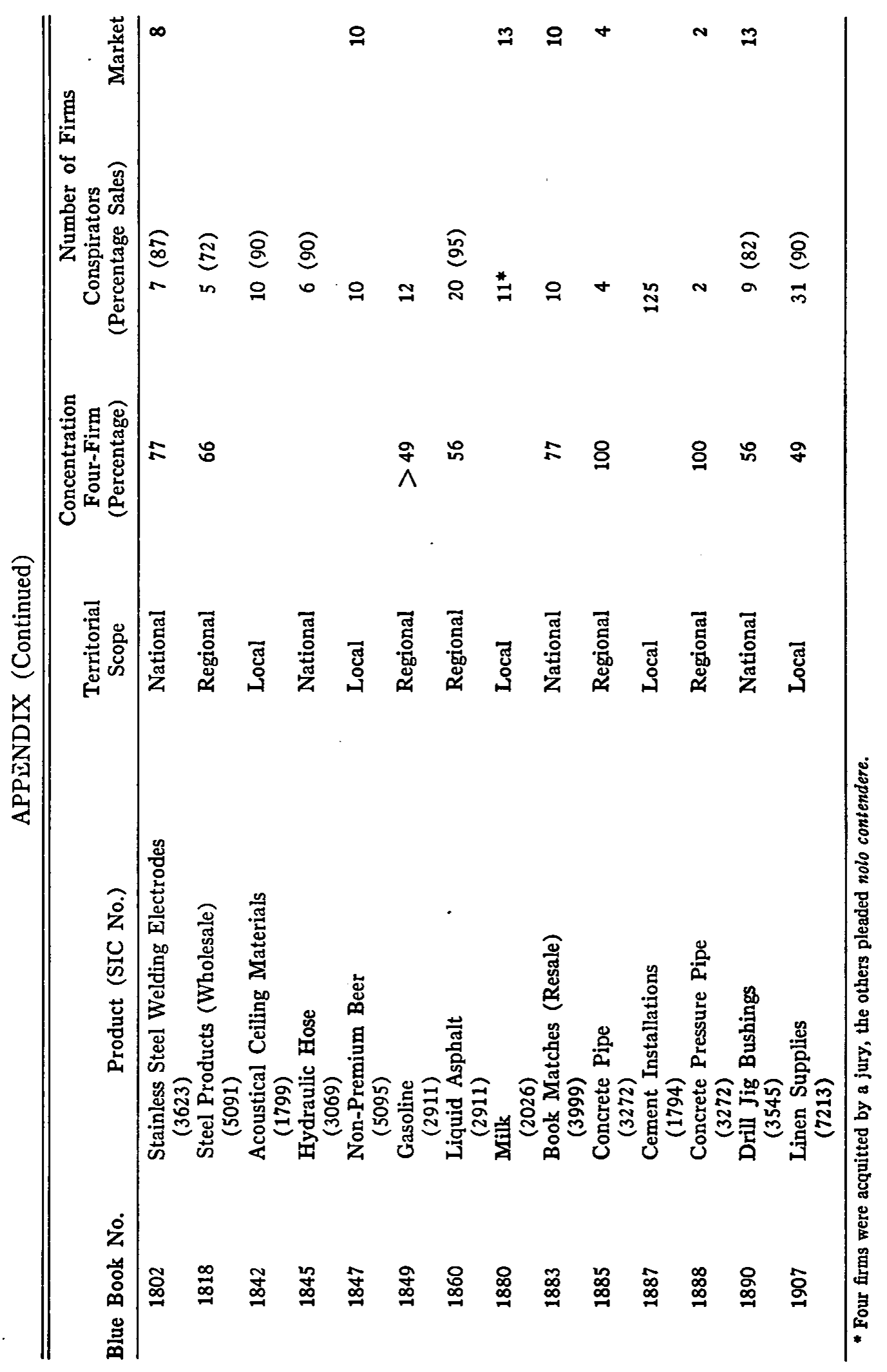


THE JOURNAL OF LAW AND ECONOMICS

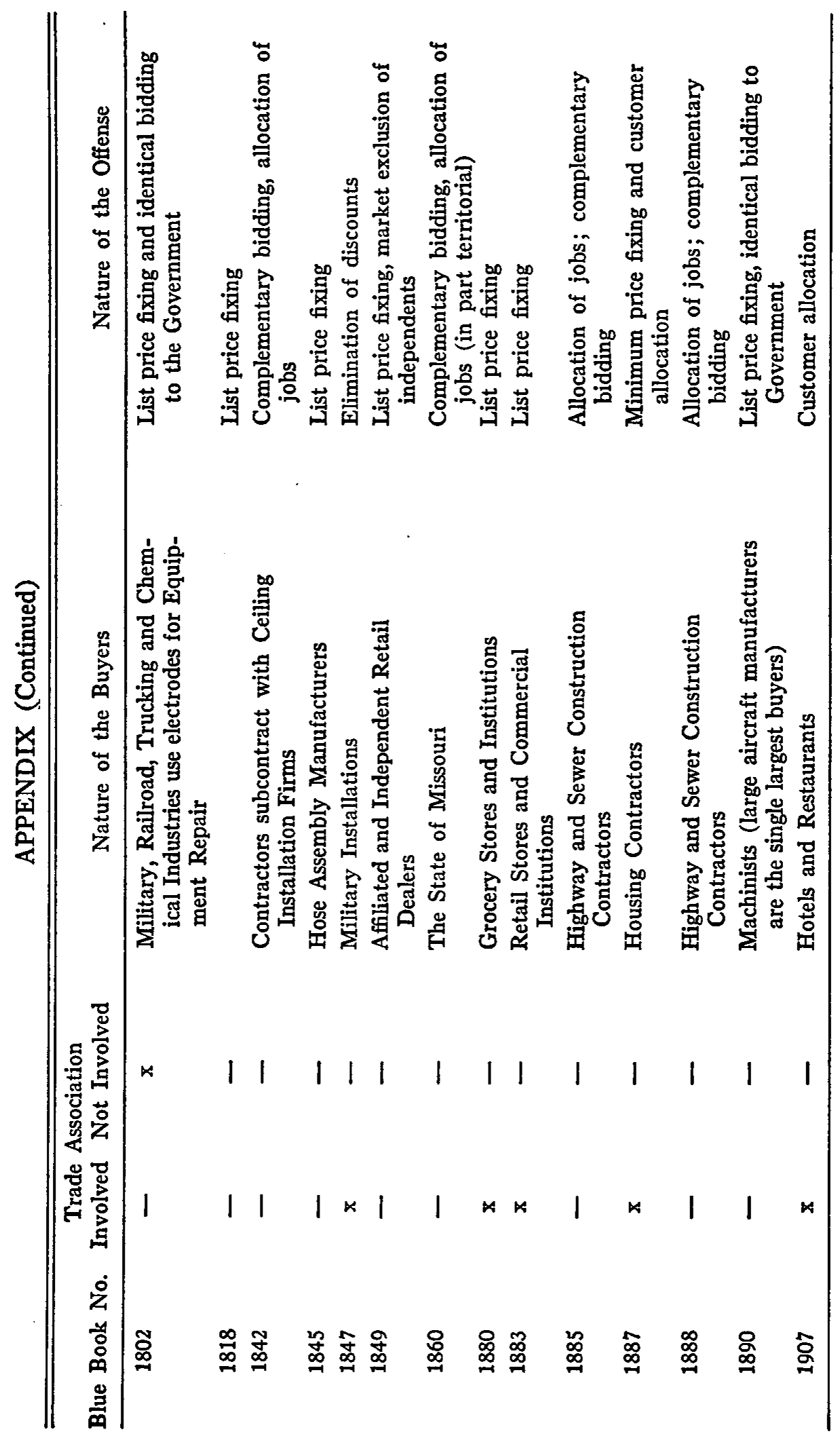


PRICE FIXING CONSPIRACIES

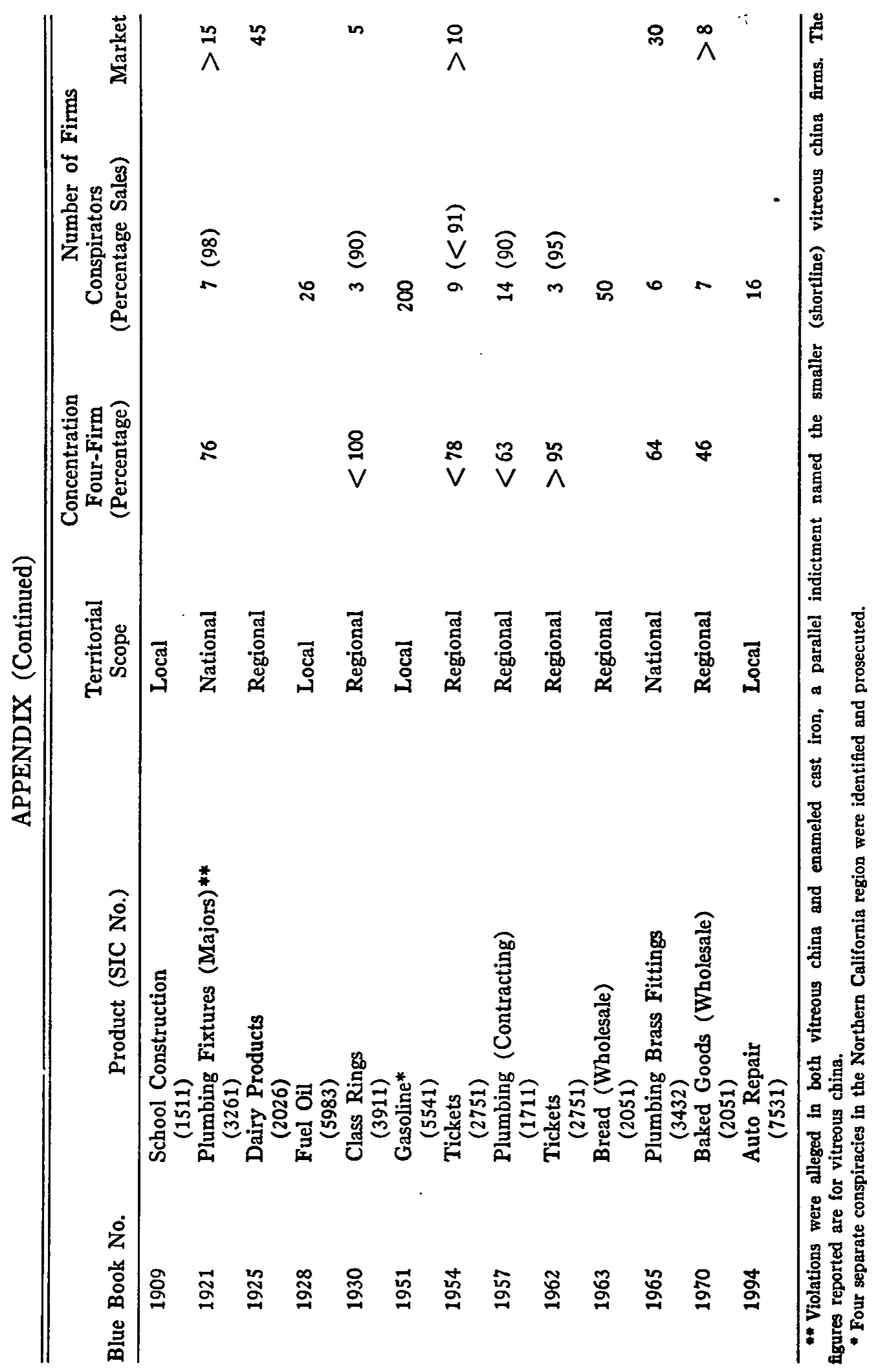


THE JOURNAL OF LAW AND ECONOMICS

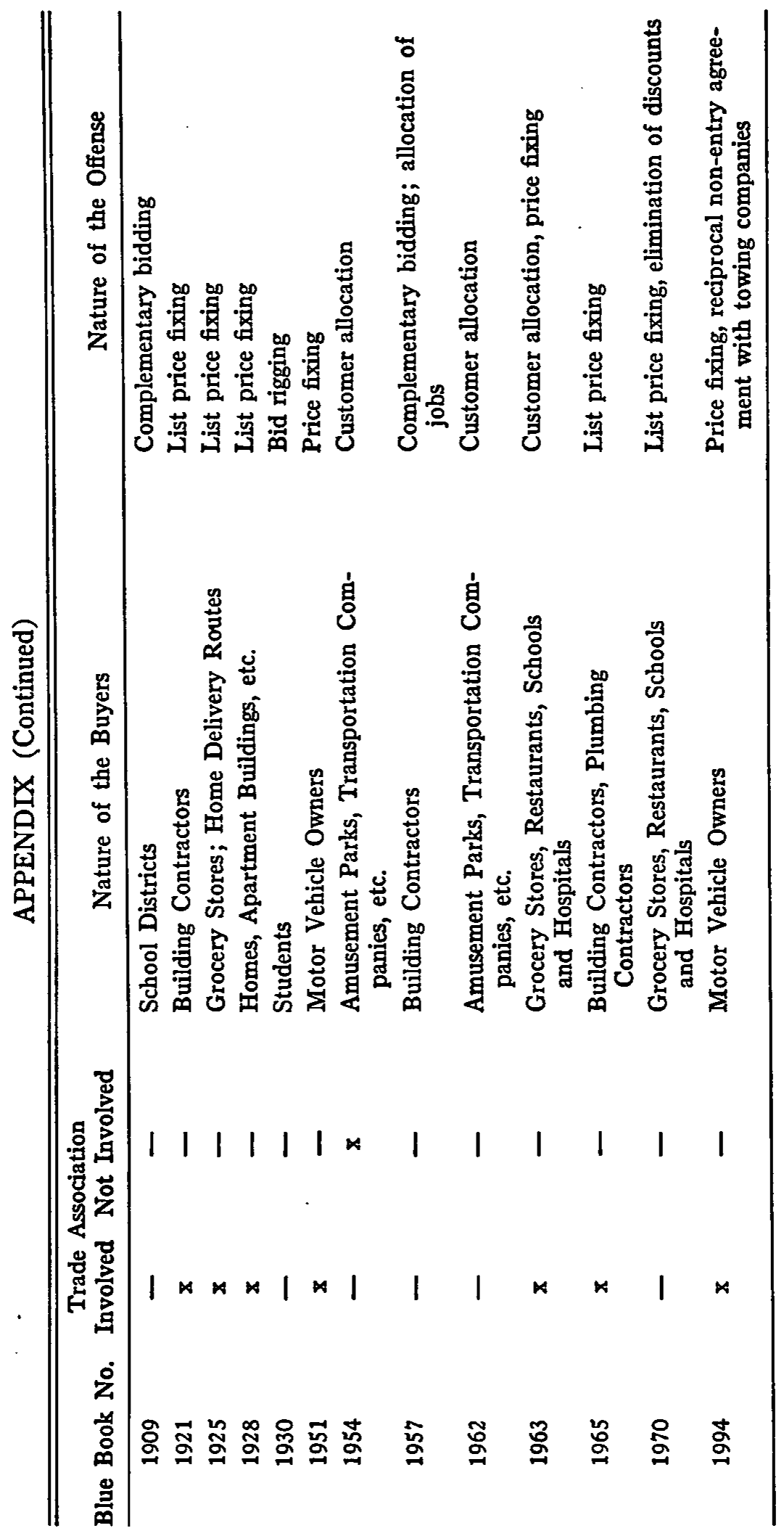


PRICE FIXING CONSPIRACIES

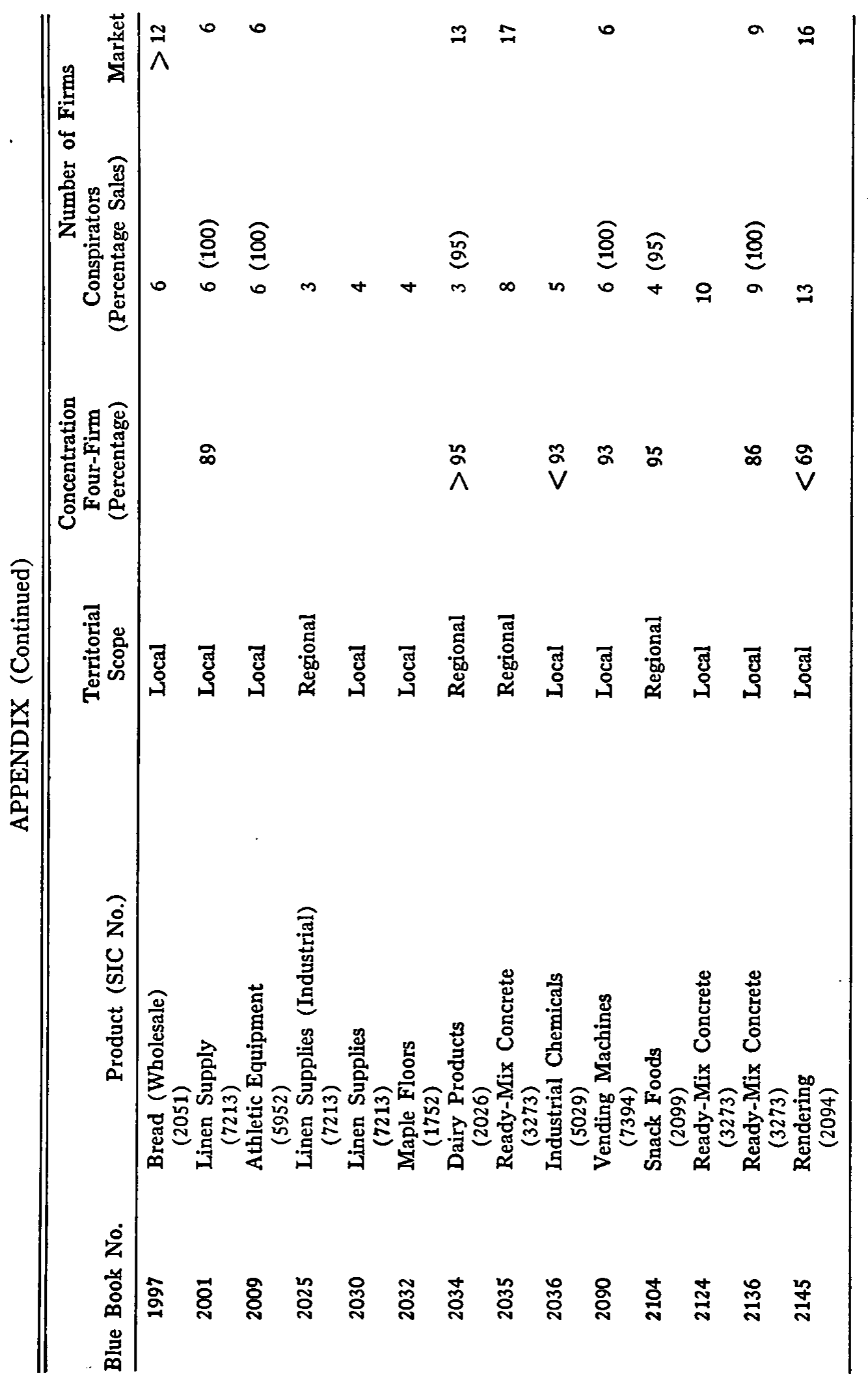




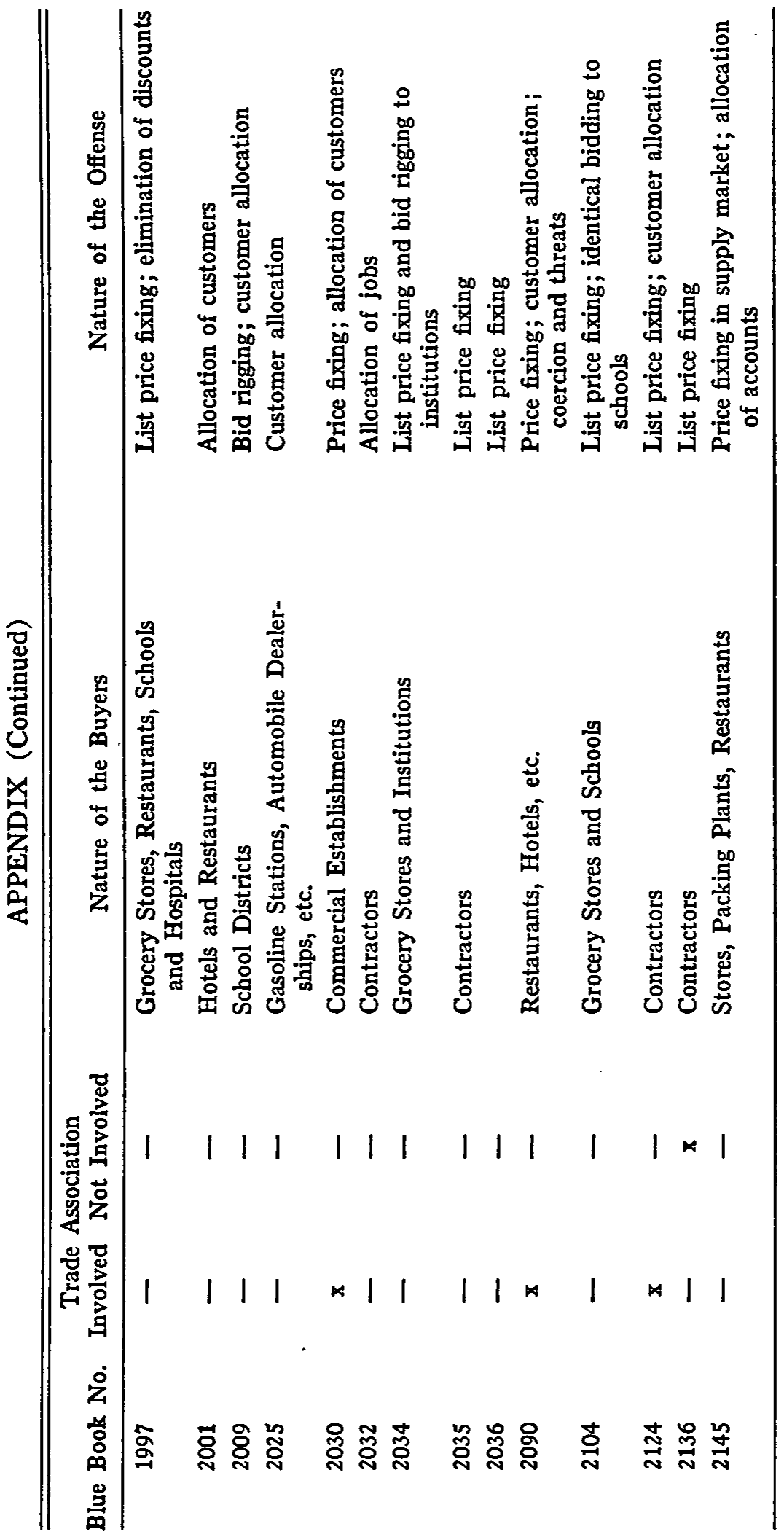


PRICE FIXING CONSPIRACIES

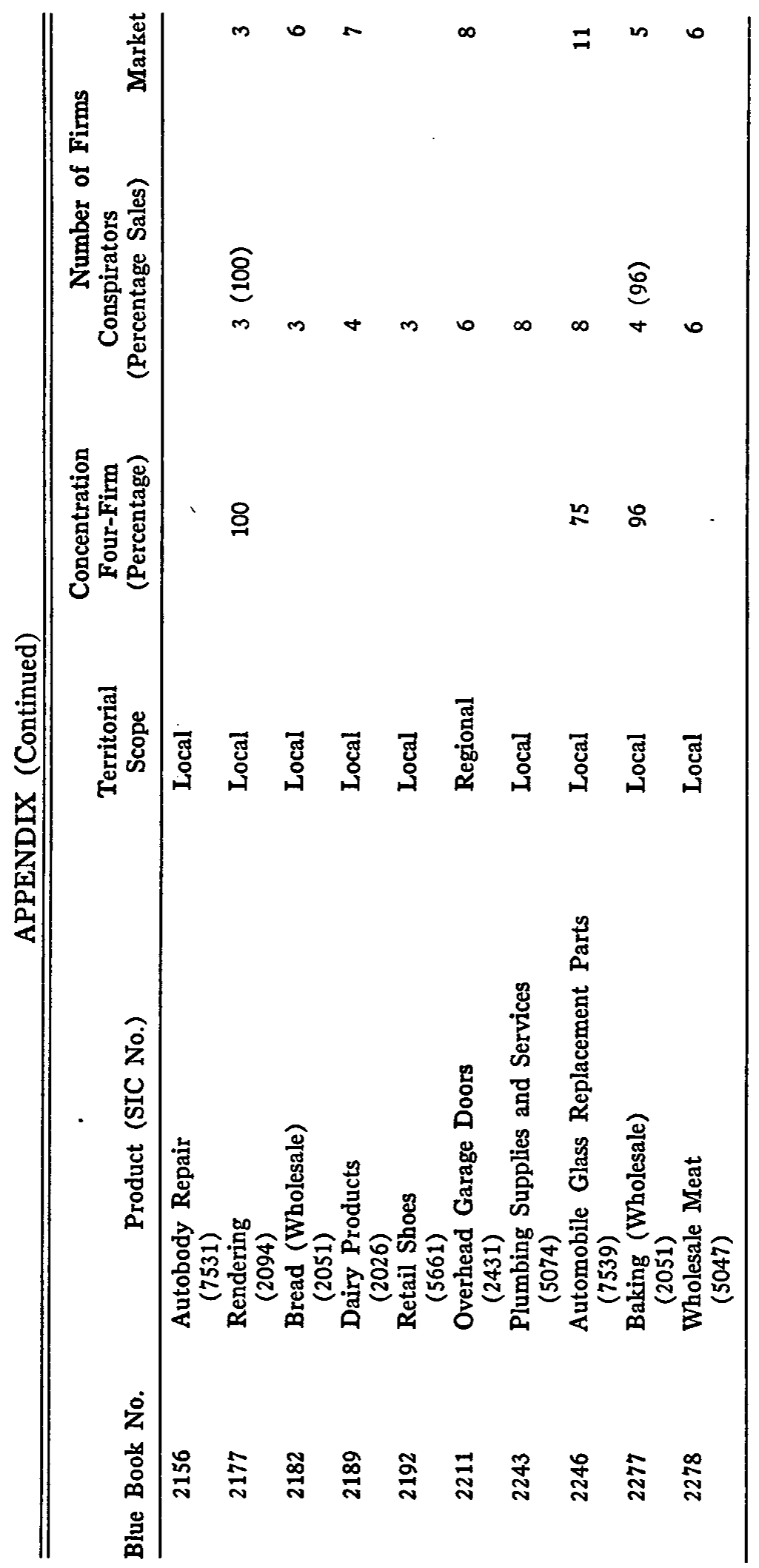




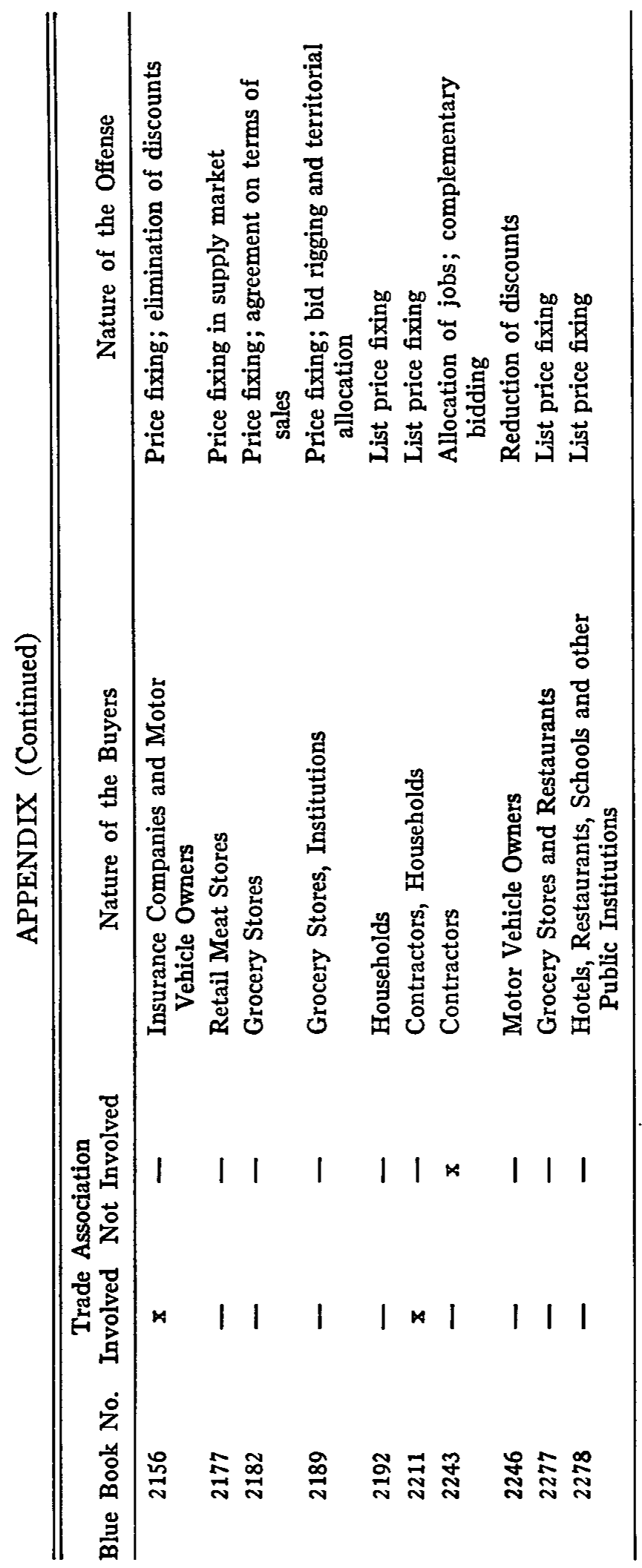

